\title{
Humanoid Robot Control System Balance Dance Indonesia and Reader Filters Using Complementary Angle Values
}

\author{
Sholihin ${ }^{1, *}$, Eka Susanti ${ }^{2}$ \\ ${ }^{1}$ Department Polytechnic of Sriwijaya, Srijaya Negera Street, Bukit Besar, Palembang - Indonesia \\ ${ }^{2}$ Department Polytechnic of Sriwijaya, Srijaya Negera Street, Bukit Besar, Palembang - Indonesia
}

\begin{abstract}
The development of increasingly advanced technology, make people want to be more developed and curiosity to know more to determine the development of advanced technology. Robot is a tool that can be used as a tool for people who have several advantages. Basically humanoid robot is a robot that resembles a human being with all the driving structure. In the application of this humanoid robot manufacture researchers use MPU6050 module which is an important component of the robot because it can provide a response to the angle reference axis $\mathrm{X}$ and $\mathrm{Y}$ reference axis, the reading corner still has noise if not filtered out beforehand. On the other hand the use of Complementary filters are the answer to reduce the noise. By arranging the filter coeffic ients and time sampling filter that affects the signal updates corner. The angle value will be the value of the sensor to the process to the PID system which generates output values that are integrated with the servo pulses. Researchers will test to get a reading of the most stable angle for this experiment is the "a" or the value of the filter coeffic ient $=0.96$ and " $\mathrm{dt}$ " or the sampling time $=10 \mathrm{~ms}$.
\end{abstract}

\section{Introduction}

The ability to be a technology developed in the modern era this point is crucial, in particular the application of robot technology. One application of the conducted research is the humanoid robot that its application to be able to dance to the theme of dance that has been determined, when the robot walks then it is also necessary to balance the robot so that the robot does not fall when the robot move or walk, and therefore need to be made of a system which can control the balance of the humanoid robot so that the robot has become more balanced and able to minimize interference from outside. The parameters that will be used to control systems that balance is the tilt position of the robot body to the reference axis $\mathrm{X}$ and the reference axis $\mathrm{Y}$. The slope of the robot is obtained by what angle parameter robot will fall. To get the angles can be searched by the formula on MPU6050, but the angle with the formula it still has a readout noise so that the angle obtained is not so good. Complementary application of filter is one filter that can improve the reading corner robot movement.

\section{Supporting theory}

\subsection{Robot}

The robot is a mechanical device that can perform physical tasks, both in the monitoring and control of human, or use a program that has been defined in advance in artificial intelligence. Robots are usually used for heavy duty, dangerous and dirty jobs repeatedly. Usually most industrial robots used in manufacturing. The applicability of other robotic included for cleaning up toxic waste, the exploration of outer space and under water, mining, jobs "find and help" (search and rescue), and search for mines. Lately the robot began to enter the consumer market in the fields of entertainment, and a housekeeper tool, such as vacuum cleaners and lawn mowers [1,2].

\subsection{Arduino Mega 2560}

Arduino Mega 2560 is a microcontroller based development board arduino using ATmega chip 2560. This board has a pin I / O that is quite a lot, some 54 pieces of digital I / O pin (pin 15 of which is PWM), 16 analog input pin, 4 pin UART (serial port hardware). Arduino Mega 2560 is equipped with a $16 \mathrm{MHz}$ oscillator, a USB port, DC power jack, ICSP header, and a reset button. This board is very complete, it has everything needed for a microcontroller [3].

\footnotetext{
Corresponding author: hin00308@yahoo.com
} 


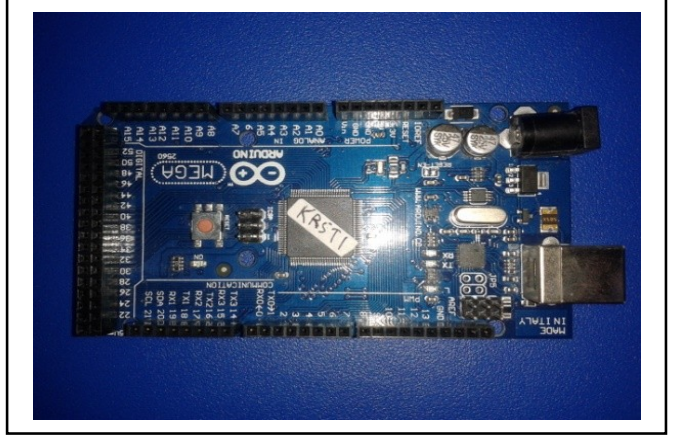

Fig. 1. Arduino Mega 2560

\subsection{Sensor}

The sensor is a component that is used to detect a physical quantity into electrical quantities that can be analyzed with a particular electrical circuit. Sensors very important role in the world of robotics which function as a robot navigational input, while the types of sensors that sound sensors, light sensors, pressure sensors fire, temperature sensors, humidity sensors, ultrasonic sensors, magnetic sensors $[4,5]$.

\subsection{MPU6050 module, gyrescope, and accelerometer}

Module MPU6050 a balance sensor that can read the angular velocity and the angular velocity. MPU6050 an IC comprising digital accelerometer and gyroscope which each have a 3 axis, both accelerometer and gyroscope that exist in MPU6050 has a 16 bit output [9]. Decision accelerometer values is done by the following formula :

Pich $=\arctan \left(-\mathrm{x} / \mathrm{z}^{2}+\mathrm{y}^{2}\right) \times(360 / 2 \mathrm{pi})$

Roll $=\arctan \left(\mathrm{y} / \mathrm{z}^{2}+\mathrm{x}^{2}\right) \mathrm{x}(360 / 2 \mathrm{pi})$

MPU6050 module has a selection maximum scale gyroscope readings can be selected, which is $250 \mathrm{deg} /$ sec, $500 \mathrm{deg} / \mathrm{sec}, 1000 \mathrm{deg} / \mathrm{sec}, 2000 \mathrm{deg} / \mathrm{sec}$.

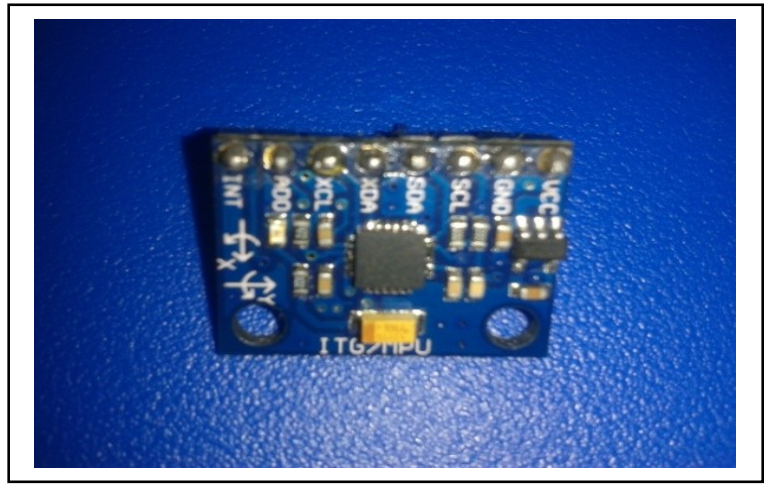

Fig. 2. MPU6050 Module

Sensor gyroscope module MPU6050 own digital outputs 16 bits, so as to perform the conversion to detection to the angular velocity, this output must be divided by the divisor factor that is different on each scale were selected. as shown in the table below;
Table 1. Scale Factor Measurement and Dividers MPU6050

\begin{tabular}{|c|c|c|}
\hline No. & $\begin{array}{c}\text { Scale } \\
\text { (deg/sec) }\end{array}$ & $\begin{array}{c}\text { Dividing Factor } \\
\text { (LSB/deg/sec) }\end{array}$ \\
\hline 1. & 250 & 131 \\
\hline 2. & 500 & 65,5 \\
\hline 3. & 1000 & 32,8 \\
\hline 4. & 2000 & 6,4 \\
\hline
\end{tabular}

That way, the gyroscope data conversion from 16 bit ADC output to units of degrees / second, so; $\omega=$ Output ADC divided by the divider factor $[5,6]$.

\section{5 complementary filter}

Complementary Filter is a recursive digital filter to estimate the condition of any process very well. Complementary filter is used as an algorithm to provide a reliable estimate the condition of the state of the process. Complementary Filters are also used to control systems that are sensitive to noise from the environment because it minimizes the square error [4]. This filter can reduce noise from the measurement of the affected sensors before entering into the control system. In the algorithm is applied to the microcontroller with software, use discrete mathematical equations. The system to be measured must be modeled by a linear system [6].

\section{Methods}

\subsection{Design mechanical robot}

Robot skeleton is made using acrylic material and PLA filament, using a $3 \mathrm{D}$ printer to process PLA filament into line servo desired shape of the container.

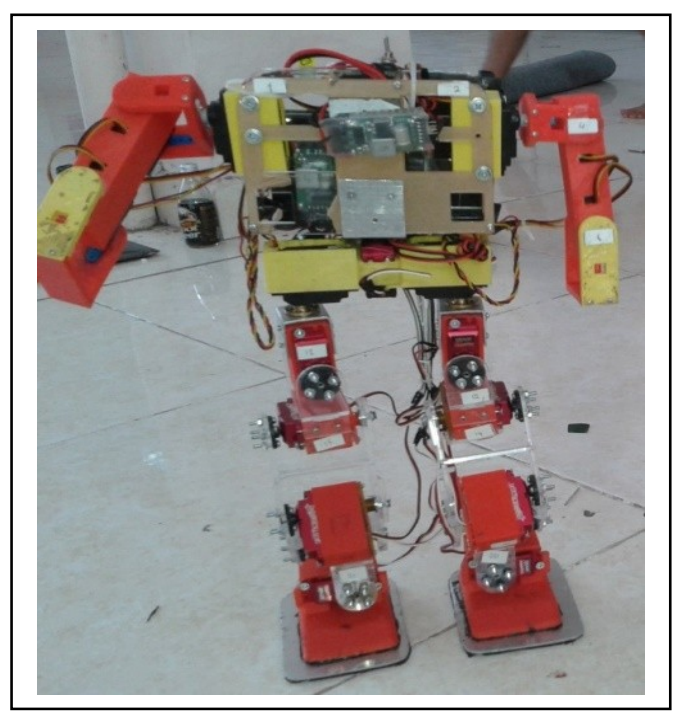

Fig. 3. Physical form Mechanical Robot 


\subsection{Flowchart robot}

Design flowchart robot is based on a balancing robot that uses an algorithm, complementary filters and PID, as follows:

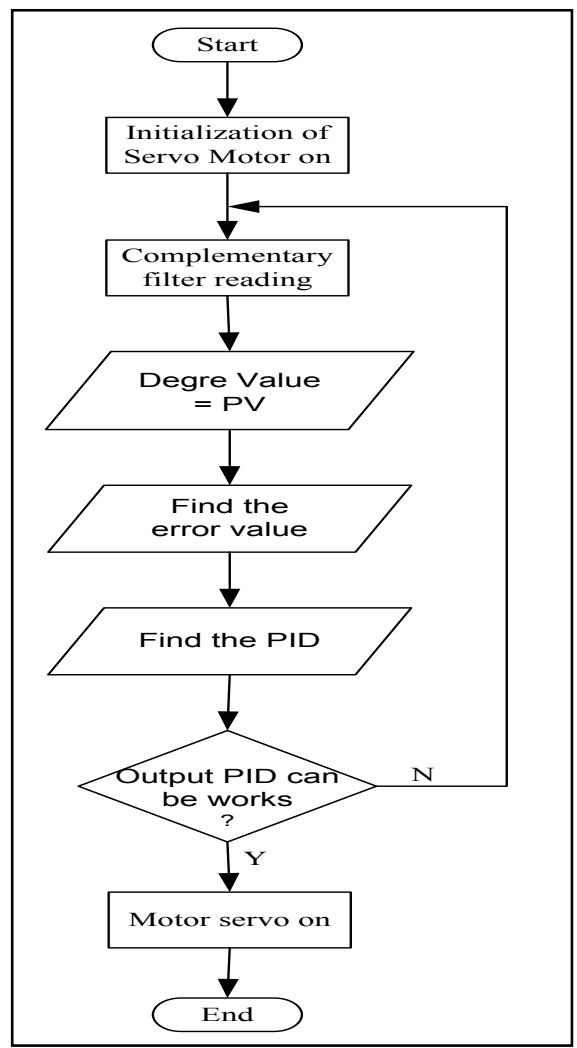

Fig. 4. Flowchart Robot

\subsection{Design of complementary filter}

On balance control processing using PID control, complementary filter function to filter the value point value or the value of the sensor modules that emit MPU6050 pitchdan roll angle. The following block diagram complementary filter design.

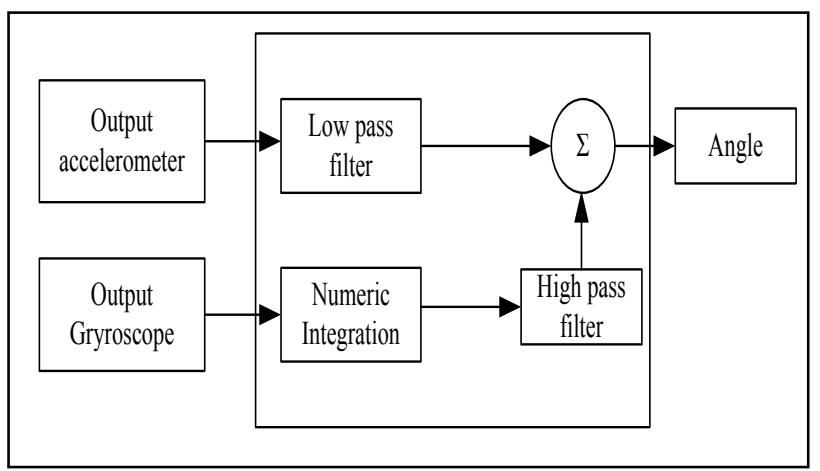

Fig. 5. Diagramm Block Complementary Filter

Using 2-axis accelerometer sensor to obtain the value of the tilt angle $(\theta)$, the axis $X$ and $Z$. Then the angle of inclination of this accelerometer in to feed the low-pass filter to eliminate noise. While Gyroscope sensor output in the form of angular velocity $(\omega)$ must be integrated in advance to get the value slope. Then fed to a high-pass filter to eliminate the effect of bias on the gyroscope. Complementary Filter is making the value of the angle in which the value of the output of the accelerometer is fed to the low pass filter is summed with the output value of the gyroscope is fed to a high pass filter which further if added together would produce a stable output value angle.

Meanwhile, the output value is stable gyroscope using the high pass filter to obtain the desired value of the speed through the corners. Here's the formula of the complementary filter.

Angle $=(a) *($ Angle + out_gyro*dt $)+(1-a) *($ Angle_acc $)$ (1)

The output of the gyroscope that form the angular velocity is added to the output value of the angle complementary previous filter, the output angle before the angle now, separated by time sampling. Here the authors chose the sampling time of 0.01 seconds or 10 ms. This value is multiplied by a factor of the filter coefficients or symbolized by "a". here the author choose the value "a" of 0.96 . That value is added to the value of output accelerometer that has not been filtered out earlier. Then tu value multiplied by the value of "1-a", so that the value of the multiplier for output accelerometer angle is 0.04 . In the complementary filter there is time constant, namely the length of real time signal, with the following formula.

$\mathrm{T}=\left(\mathrm{a}^{*} \mathrm{dt}\right) /(1-\mathrm{a})$

\section{Current results}

Complementary Filters used in digital filters or use the program. Complementary filter testing is done by doing the reading corner of the roll and pitch, as well as the results of calculations comparing data with the filter without filter. At the first measurement, the value of the filter coefficients (a) will be changed - a change of 0.6 ; $0.8 ; 0.96$ as well as the sampling time (dt) fixed at 10 $\mathrm{ms}$. Here is the response signal output from the complementary filter. Red line is the sensor output accelerometer, gyroscope sensor output is black and blue is the output signal of the complementary filter.

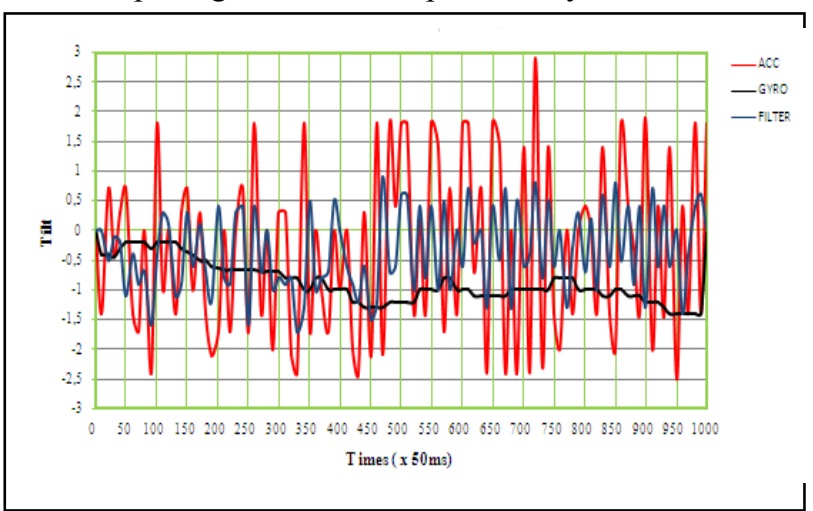

Fig. 6. Filter coefficient 0.6 was stationary non-rotating 


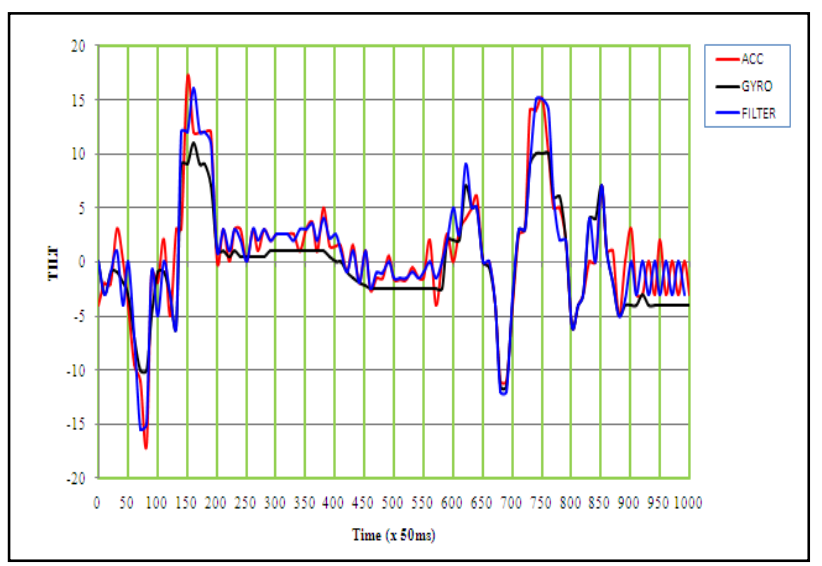

Fig. 7. Filter Cofficient 0,6 was Stationary Rotating

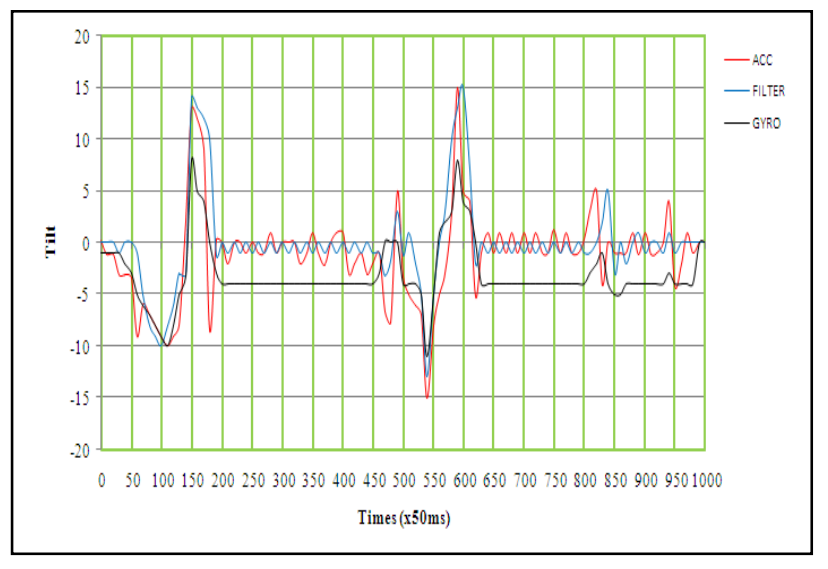

Fig. 8. Filter Coeffecint 0,8 being stationary non-Rotating

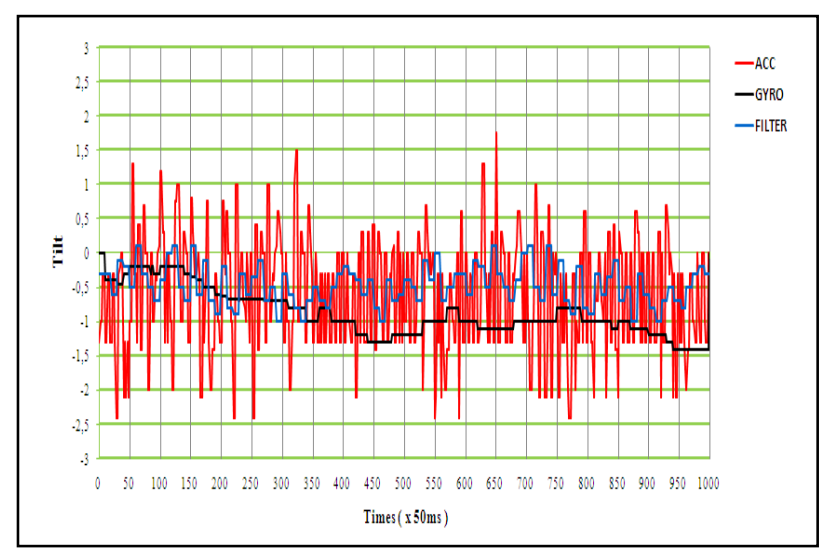

Fig. 9. Filter Coeffecient 0,8 being Stationary Rotating

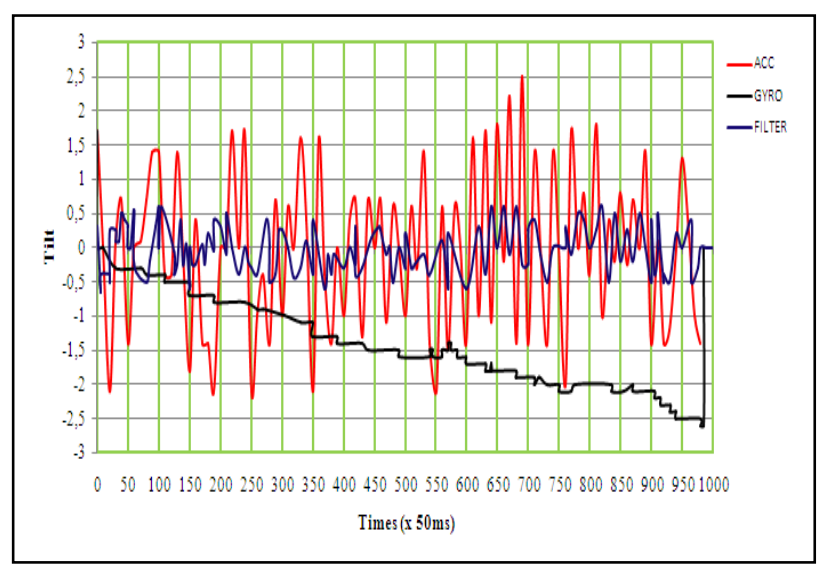

Fig. 10. Filter Coeffecient 0,96 no-Respon

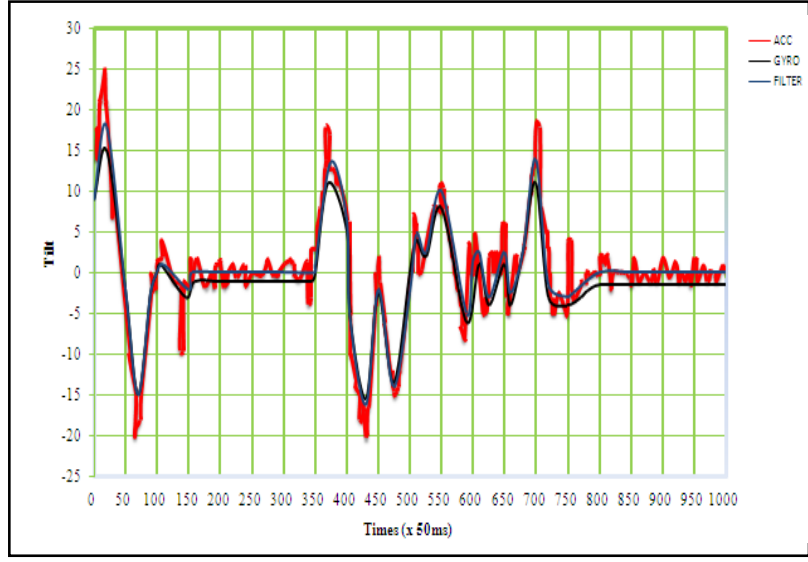

Fig. 11. Filter Coeffecinet 0,96 Respon

From some of the pictures above we can conclude the greater the value of the filter coefficients (a), the output signal will be more stable complementary filter less air noise) but will prolong the time constant resulting signal update time is getting longer. If we compare with the equation to find the value of time constant, then the above conclusions based testing will be in accordance with the equation.

Next was measured by changing change time sampling, the sampling time value will be changed to change the value of 0.1 seconds $(10 \mathrm{~Hz}), 0.05 \mathrm{sec}(20 \mathrm{~Hz})$ and 0.01 second $(100 \mathrm{~Hz})$.

Red line is the sensor output accelerometer, gyroscope sensor output is black and blue are complementary filter output signal.

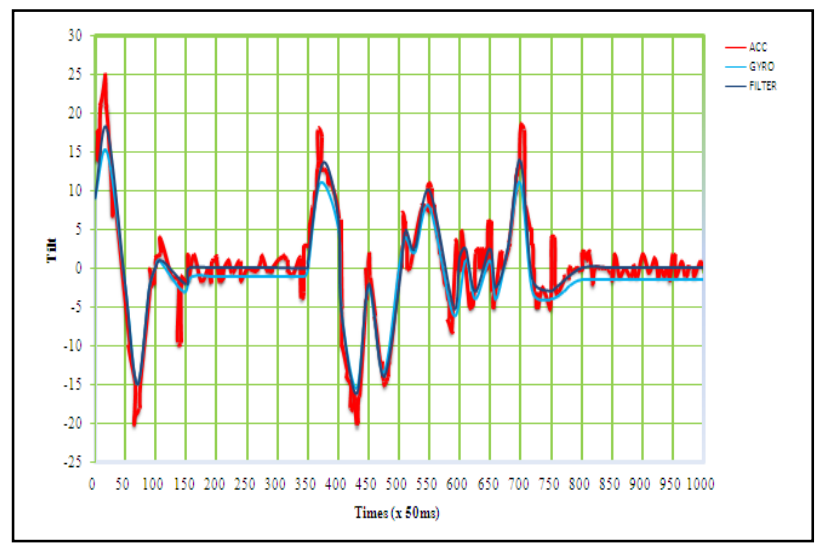

Fig. 12. Time Sampling with 0,01 second

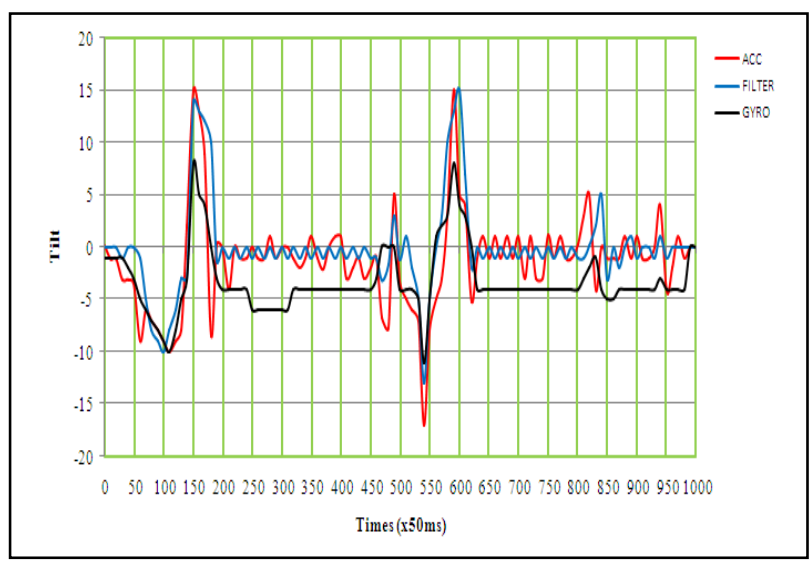

Fig. 13 Time Sampling with 0,05 second 


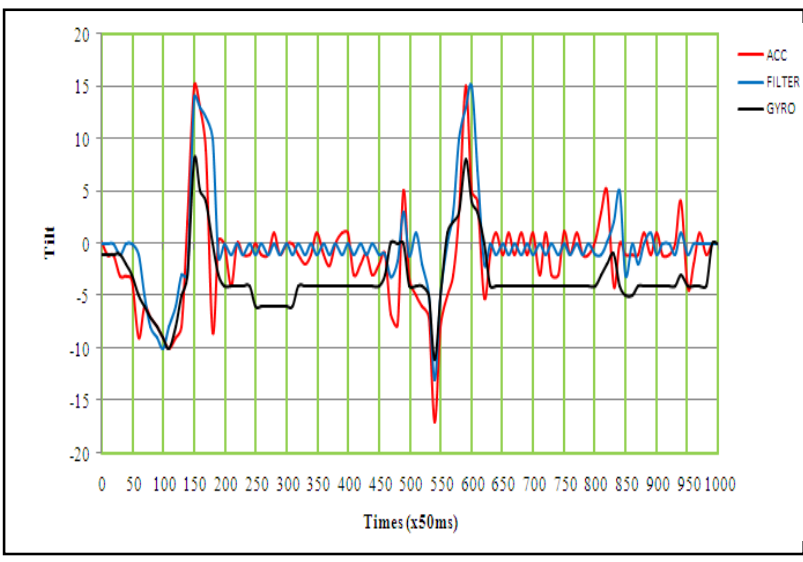

Fig. 14. Time Sampling with 0,1 second

It can be concluded that the faster sampling time used the faster time constant of the output signal complementary filter. Again if we look at the equation for calculating the time constant, the output signal complementary filter testing, will be in accordance with the theory of equations to calculate the value time constant.

Selection of the value of the filter coefficients (a) and the sampling time (dt) shall be adjusted to the response on the application you want to create. If the response is fast, it is advisable to accelerate the value of time constant, and if the response to the application system that we created is relatively slow, then the value of time Constans the complementary filter algorithm we can make relatively longer.

\section{Conclusion}

In making this humanoid robot dance filter coefficient values corresponding to the sensor MPU6050 is 0.96 because the robot should have a fast response on balance to keep from falling while dancing. If the sampling time accelerated the signal sampling time is faster and has a faster response. Selection of the value of the filter coefficients (a) and the sampling time (dt) must be adapted to respond to the application that you created. If the system response desired application quickly, it is advisable to accelerate the value of time constant, and if the system response to the application that you created relatively slowly, the time constant value at the algorithm complementary filter you can make relatively longer.

\section{References}

1. Asma Bait Fadhah, Athra' Al-Lawati, Sara AlMaskari, Abderezak Touzene and Ahmed AlKindi, Applications of Digital Information and Web Technologies,p. 151-155, (2008)

2. W. Budiharto, and Nawalan, Membuat Sendiri Robot Humanoid. Jakarta: Elex Media Komputindo.

3. Eka, Yulius. 2011.Buku Pintar Pemrograman C\#. Yogyakarta: Media Kom, (2009)

4. Gourab Sen Gupta, S.C. Mukhopadhyay, Matthew Finnie-" WiFi-based Control of a Robotic Arm with Remote Vision" I2MTC International Instrumentation and Measurement Technology Conference, Singapore, (2009)

5. Carlos Cardei and Jose Sa da Costa, in Industrial Electronics Societ, p. 1-6., (2005)

6. Johan, Pramudita, Sistem Kontrol Keseimbangan Statis Robot Humanoid Joko Klana Berbasis Pengontrol PID. Elektronika dan Instrumentasi. Universitas Gadja Mada. Yogyakarta, (2013)

I. Maulana, Susilo, A,Robot Humanoid dan Kecerdasan Buatan, Jurusan Teknik Komputer, Fakultas Teknik, STIMIK-AKI, Semarang (2010)

7. Munir, Rinaldi, Algoritma \& Pemrograman Dalam Bahasa Pascal dan C. Bandung: Elex Media Komputindo,(2009)

8. Nurfansyah, Rahadian, Estimasi Sudut Orientasi Menggunakan Sensor 6 DOF IMU dan Sensor Magnetometer 3 aksis, thesis of Dept Elctro, Universitas Diponegoro,Semarang. Volume 6, No. 1. 3 Juli (2013).

9. Septian, Taufik dwi suyadh, Buku Pintar Robotika.Yogyakarta : Andi,( 2010)

10. Setyono, Arif, Perancangan Perangkat Lunak Pendeteksi Posisi Benda 6 Derajat Kebebasan, Tesis of Dept Electro, Universitas Diponegoro, Semarang. Volume 3, No. 2. 10 Juli (2016) 